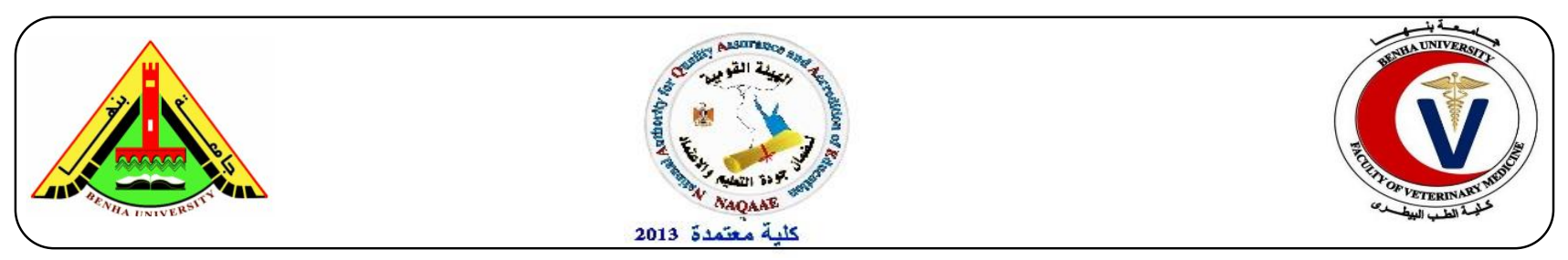

\title{
Demonstration of oxytetracycline residues in cattle meat and offal
}

\author{
Ibrahim, Hemmat M.; Hassan, M.A. and Gouda, Manar Y.
}

Food Hygiene and Control Department, Faculty of Veterinary Medicine, Benha University.

\section{A B S T R A C T}

Accurately, ninty samples of meat, liver and kidneys were collected from abattoirs from different places in Qalyobia and Gharbia governorates for detection of their oxytetracycline residues by using HPLC and various cooking methods (boiling, frying and grilling) were applied on beef and offal for detection and study the effect of heat treatment on such antibiotic residue levels. The obtained results indicated that oxytetracycline residues were detected in $23.33 \%, 33.33 \%$ and $40 \%$ of the examined samples of beef, liver and kidneys, respectively and the level of OTC residues $(\mu \mathrm{g} / \mathrm{kg})$ in the examined samples of meat, liver and kidneys ranged from 26.8 to 346.5 with mean value of $151.79 \pm 11.64$, from 58.1 to 1921.4 with mean value of $822.56 \pm 37.36$ and from 72.3 to 3118.9 with mean value of $1457 \pm 42.81$, respectively. Accurately, $90 \%, 80 \%$ and $76.67 \%$ of examined samples of beef, liver and kidneys, respectively were accepted. This accordance to MRL of OTC $(200 \mu \mathrm{g} / \mathrm{kg}$ for meat , 600 $\mu \mathrm{g} / \mathrm{kg}$ for liver and $1200 \mu \mathrm{g} / \mathrm{kg}$ for kidneys) which stipulated by US code of federal regulations (2003), FAO/WHO (2004), Egyptian Organization of Standardization and Quality Control "EOSQC" No. 3692 (2008). The effect of different cooking methods (boiling, frying and grilling) on oxytetracycline (OTC) residues in beef and offal samples revealed that before boiling, frying and grilling the concentration of OTC residues in cattle meat were $26.8 \mathrm{ug} / \mathrm{kg}, 195.2 \mathrm{ug} / \mathrm{kg}$ and 346.5 $\mathrm{ug} / \mathrm{kg}$. After boiling, the concentrations of OTC residues were $0 \mathrm{ug} / \mathrm{kg}, 12.4 \mathrm{ug} / \mathrm{kg}$ and $198.9 \mathrm{ug} / \mathrm{kg}$ and the reduction $\%$ was $100 \%, 93.7 \%$ and $42.6 \%$, respectively. After frying, the concentrations of OTC residues were $0 \mathrm{ug} / \mathrm{kg}, 0 \mathrm{ug} / \mathrm{kg}$ and $57.1 \mathrm{ug} / \mathrm{kg}$ and the reduction $\%$ was $100 \%, 100 \%$ and $83.5 \%$, respectively. After grilling, the concentration of OTC residues were 0,0 and $26.8 \mathrm{ug} / \mathrm{kg}$ and reduction $\%$ was $100 \%, 100 \%$ and $92.3 \%$, respectively.

Keywords: Cattle meat, liver, kidney, oxytetracycline residues.

(http://www.bvmj.bu.edu.eg) $\quad$ (BVMJ-35(2): 202-208, 2018)

\section{INTRODUCTION}

Due to the demand for increasing meat production, several agents have been employed for growth promotion and for animal treatment and these include various types of antibiotics (Mahgoub et al., 2006). Some of antibiotics leave residues in the animal tissues and may cause some hazard to human health due to consumption of food stuffs of animal origin containing antibiotic residues. The presence of antibiotic residues in food is potentially hazardous to health as it may cause allergic reactions in people, sensitization of any antibiotic resistance and imbalance of intestinal microflora. In addition, antibiotics 
may influence starter cultures in food industry and lead to economic loss (Kirbis, 2007). The heat treatment decreases the concentration of residues or complete inactivation according to the degree of temperature and time of exposure (Gergis, 1998). The methods used to detect antibiotic residues in food of animal origin are immuno-enzymatic, microbiological and chemical. A screening method is the first hand analysis of sample to show the presence or absence of residues and microbiological methods are suitable for large scale screening because of their broad spectrum characteristics (Aerts et al,. 1995).

\section{Materials and methods}

\subsection{Collection of samples:}

Ninety random samples of beef, liver and kidney (30 of each) were collected from different abattoirs in Qalyobia and Gharbia governorates. Each sample was kept in a plastic bag and preserved in an ice box then transferred to the laboratory without undue delay. All collected samples were examined to determine their contents of OTC residues as well as their safety for human consumption.

\subsection{Determination of oxytetracycline residues}

2.2.1. Extraction of the drug from the sample:

Two grams of each organ to be analyzed were weighed using digital balance and then cut into very small pieces and subsequently ground into fine powder using Sartorius mincer.

\subsubsection{Chromatographic condition:}

Detection was performed with photodiode array (PDA) detector set at $350 \mathrm{~nm}$ wave length. Quantification of residues in samples was obtained and calculated from areas under curves extrapolated automatically by the software (Chromo Quest 5).

\subsubsection{Calibration curve:}

The curve was prepared by using concentrations of 10,20,30,40,50 and 60 $\mathrm{ug} / \mathrm{L}$ of oxytetracycline in eluent. These standards were prepared from the daily prepared stock solution and treated as $100 \mathrm{mg}$ of oxytetracycline standard was accurately weighed and put in a $100 \mathrm{ml}$ volumetric flask, the powder was dissolved in $100 \mathrm{ml}$ of methanol to make a stock solution. The detection limit for oxytetracycline was 0.01 ppm, while the retention time was 3.9 minutes. 2.3. Quantization of the amount of OTC residue by peak height or peak area analysis: Spiked samples were prepared by adding 500 $\mu \mathrm{l}$ spiking solution to $10 \mathrm{~g}$ (oxytetracycline) control sample (free of such antibiotics) to obtain spiking levels equal to $1 \mu \mathrm{g} / \mathrm{ml}$. Accordingly, the retention time was estimated by which the concentrations of these antibiotics could be measured.

2.4. Calculation of the exact concentration of OTC residue in the examined sample in correlation to the standard curve:

A standard calibration curve was applied for each antibiotic by using 5 known standard solutions of oxytetracycline as follow:

$100 \mathrm{ppb}$ oxytetracycline.

200 ppb oxytetracycline.

$300 \mathrm{ppb}$ oxytetracycline

$400 \mathrm{ppb}$ oxytetracycline

$500 \mathrm{ppb}$ oxytetracycline

Therefore, the actual concentrations of oxytetracycline could be estimated.

\subsection{Experimental Part (Heat treatment):}

three positive samples of beef containing low, medium (around permissible limit) were subjected to certain cooking methods either boiling, frying or grilling which applied as ordinary cooking methods at home. Accordingly, heat treatments of beef as boiling were carried out at $100^{\circ} \mathrm{C}$ for 30 minutes in a pan; frying in neutral oil at $190^{\circ} \mathrm{C}$ for 10 minutes and grilling at $200^{\circ} \mathrm{C}$ for 15 minutes were applied until the core temperature of the tested samples reached $74^{\circ} \mathrm{C}$. Further, application of HPLC on such tested beef samples was adopted to determine the efficacy of each cooking method on the stability of oxytetracycline. 


\subsection{Statistical Analysis:}

Application of Analysis of Variance (ANOVA) was adopted for statistical evaluation of the obtained results according to Feldman et al. (2003).

\section{RESULTS}

From the results reported in table 1 it is obvious that oxytetracycline residues were detected in $23.33 \%, 33.33 \%$ and $40 \%$ of the examined samples of beef, liver and kidneys, respectively. Table (2) indicated that the level of oxytetracycline residues $(\mu \mathrm{g} / \mathrm{kg})$ in the examined samples of beef, liver and kidneys ranged from 26.8 to 346.5 with mean value of $151.79 \pm 11.64$; from 58.1 to 1921.4 with mean value of $822.56 \pm 37.36$ and from 72.3 to 3118.9 with mean value of $1457 \pm 42.81$, respectively. Differences associated with the examined samples of beef, liver and kidneys were highly significant $(\mathrm{P}<0.01)$ as a results of their contents of oxytetracycline residues as shown in table (3). Accurately, 90\%, 80\% and $76.67 \%$ of examined samples of beef, liver and kidneys were accepted, respectively (table 4). This accordance to MRL of OTC $(200 \mu \mathrm{g} / \mathrm{kg}$ for beef , $600 \mu \mathrm{g} / \mathrm{kg}$ for liver and $1200 \mu \mathrm{g} / \mathrm{kg}$ for kidneys) which stipulated by US code of federal regulations (2003), FAO/WHO (2004), Egyptian Organization of Standardization and Quality Control "EOSQC" No. 3692 (2008) . Results achieved in table (5) revealed the effect of different cooking methods (boiling, frying and grilling) on oxytetracycline (OTC) residues in cattle meat samples. Before boiling, frying and grilling, the concentration of OTC residues in beef were $26.8 \mathrm{ug} / \mathrm{kg}, 195.2 \mathrm{ug} / \mathrm{kg}$ and $346.5 \mathrm{ug} / \mathrm{kg}$. After boiling, the concentrations of OTC residues were $0 \mathrm{ug} / \mathrm{kg}$, $12.4 \mathrm{ug} / \mathrm{kg}$ and $198.9 \mathrm{ug} / \mathrm{kg}$ and the reduction $\%$ was $100 \%, 93.7 \%$ and $42.6 \%$, respectively. After frying, the concentrations of OTC residues were $0 \mathrm{ug} / \mathrm{kg}, 0 \mathrm{ug} / \mathrm{kg}$ and $57.1 \mathrm{ug} / \mathrm{kg}$ and the reduction $\%$ was $100 \%, 100 \%$ and $83.5 \%$, respectively. After grilling, the concentration of OTC residues were 0,0 and $26.8 \mathrm{ug} / \mathrm{kg}$ and reduction\% was $100 \%, 100 \%$ and $92.3 \%$, respectively.

Table 1: Incidence of oxytetracycline residues detected in the examined samples of beef and offal $(n=30)$.

\begin{tabular}{lll}
\hline Cattle tissues & No. & $\%$ \\
\hline Meat & 7 & 23.33 \\
Liver & 10 & 33.33 \\
Kidneys & 12 & 40 \\
Total (90) & 26 & 28.89 \\
\hline
\end{tabular}

Table 2: Statistical analytical results of oxytetracycline residues (ppb) in the examined samples of beef and offal $(n=30)$.

\begin{tabular}{cccc} 
Cattle tissues & Min. & Max. & Mean \pm S.E* \\
& & & \\
\hline Meat & 26.8 & 346.5 & $151.79 \pm 11.64$ \\
Liver & 58.1 & 1921.4 & $822.56 \pm 37.36$ \\
Kidneys & 72.3 & 3118.9 & $1457.12 \pm 42.81$
\end{tabular}

S.E* $=$ Standard error of mean 
Table 3: Analysis of Variance (ANOVA) of oxytetracycline residues in the samples of beef and offal.

\begin{tabular}{lllll}
\hline Source of Variance & D.F & S.S & M.S & F. value \\
\hline Total & 89 & 124.3372 & & \\
Between Tissues (T) & 2 & 34.8490 & 17.4245 & $16.94++$ \\
Error & 87 & 89.4882 & 1.0286 & \\
\hline
\end{tabular}

$\begin{array}{lc}\text { D.F }=\text { Degree of Freedom } & \text { S.S }=\text { Sum Squares } \\ \text { M.S }=\text { Mean Squares } & ++=\text { High significant differences }(\mathrm{P}<0.01)\end{array}$

Table 4: Acceptability of the examined samples of beef and offal according to their levels of oxytetracycline residues $(\mathrm{n}=30)$.

\begin{tabular}{cccccc} 
Cattle tissues & $\begin{array}{c}\text { Maximum Residual } \\
\text { Limit }(\mathrm{ppb})^{*}\end{array}$ & \multicolumn{2}{c}{ Accepted samples } & \multicolumn{2}{c}{ Unaccepted samples } \\
& 200 & 27 & 90 & No & $\%$ \\
Meat & 600 & 24 & 80 & 6 & 10 \\
Liver & 1200 & 23 & 76.67 & 7 & 23.33 \\
Kidneys & & 74 & 82.22 & 16 & 17.78 \\
Total (90) & & & & & \\
\hline
\end{tabular}

* Egyptian Organization of Standardization “EOS” No. 3692 (2008)

Table 5: Effect of various cooking methods on the oxytetracycline residues in beef.

\begin{tabular}{cccccccc}
\hline \multirow{2}{*}{ Trial } & \multirow{2}{*}{ Control } & \multicolumn{2}{c}{ Boiling } & \multicolumn{2}{c}{ Frying } & \multicolumn{2}{c}{ Grilling } \\
& & Content & Reduction \% & Content & Reduction \% & Content & Reduction \% \\
\hline 1 & 26.8 & 0 & 100 & 0 & 100 & 0 & 100 \\
2 & 195.2 & 12.4 & 93.7 & 0 & 100 & 0 & 100 \\
3 & 346.5 & 198.9 & 42.6 & 57.1 & 83.5 & 26.8 & 92.3 \\
\hline
\end{tabular}

\section{DISCUSSION}

The current results come in accordance with those reported by Rome (1991) who reported that the highest residual level of oxytetracycline was recorded in kidney and liver while the lower level was in muscle. The obtained results are higher than those reported by Thomas (1994) and Olufemi and Agboola
(2009) who reported that out of 180 beef samples collected from Nigeria and analyzed by HPLC, 98 of the total samples had detectable levels of oxytetracycline residues. The mean residues for positive samples were $51.8 \mu \mathrm{g} / \mathrm{kg}, 372.7 \mu \mathrm{g} / \mathrm{kg}$ and $1197.7 \mu \mathrm{g} / \mathrm{kg}$ for muscle, kidney and liver, respectively. Lower results were reported by Shahid et al. (2007) who recorded that out of 29 samples of meat were analyzed for OTC residues, 13 (44.8\%) 
had detectable residue levels for OTC and 6 (20.7\%) had higher residue levels than recommended MRL. The mean residual levels in liver, kidneys and muscle samples were $1.274,2.119$ and $0.05 \mu \mathrm{g}$ g-1, respectively.

Accordingly, the highest incidence of oxytetracycline residues was recorded in liver and kidneys and the lowest was in the muscle. This might be expected in cases where antimicrobials were administered for long time before slaughter the organs of metabolism and excretion are being had higher concentrations of these residues than the muscles over time. This is also reported by Landoni \& Errecalde (1992) who recorded that the organs of metabolism and excretion were expected to be having high concentrations of residues more than the muscle over times when animal administrated antimicrobial for long time before slaughter. Also, Prescott \& Baggot (1993) mentioned that oxytetracycline is distributed widely into body tissues and the highest concentration can be found in the liver and the kidney but in the muscle and fat it was very low. The use of HPLC method for detecting the antibiotic residues in this study was confirmed by MacNeil et al. (1996) who used microbilogical and HPLC methods for the detection of the antibiotic residues. Moreover, FAO/ WHO (1998) mentioned that HPLC could identify the antibiotic at level below the MRL. The human health problems that could arise from consumption of un acceptable levels of OTC residues in meat include gastrointestinal disturbances, hypersensitivity, bone and teeth problems in children and development of bacterial resistance (Larkin et al, 2004). Nearly similar findings for the effect of different cooking methods were obtained by Rose et al. (1996) who detected that the substantial net reductions on oxytetracycline (OTC) residues in tissues after a range of cooking processes including microwaving, boiling, roasting, grilling, braising and frying were 35 to $94 \%$. The obtained results agreed with those reported by Hagsmaa (1992) and Kühne et al. (2001) who pointed out that the heat treatment for $10-15$ minutes at $100^{\circ} \mathrm{C}$ in most cases sufficient to inactivate the oxytetracycline to non-detectable residue. This asseration is also corroborated by Marouf $\&$ Bazalou (2005) who recorded that frying process reduces oxytetracycline residues concentration by $85.71 \%$. These results are in harmony with those reported by Gratacos Cubarsi et al. (2007), Javadi (2011) and Nguyen et al (2013) who reported that thermal treatments may reduce the concentration of veterinary drug residues in food. Therefore, use of proper cooking processes that have a higher temperature and longer time can lead to the most reduction in antibiotics residues in foodstuff and it can provide an additional margin of safety for consumers (Javadi, 2011). Information given by the obtained results evident that beef and offal collected from Qalyobia and Gharbia governorates generally contain residues of antibiotic agents. Most of these levels are above the acceptable limits, thus their presence may regard as a health hazard as they may cause allergic reactions or produce drug tolerant bacteria.

\section{Conclusion}

So, all attempts to reduce antibiotic residues in meat should be applied through education by veterinary personnel; rapid screening procedures for the analysis of antibiotic residues as HPLC and prohibition of meat containing antibiotics residues. Also, the observed findings may be helpful in confirming and selecting the ideal method for cooking so as to effectively reduce oxytetracyclin residues in meat prior to consumption.

\section{REFERENCES}

Aerts M. M. L., Hogenboom A. C. and Brinkman U. A. Th. (1995): Analytical 
strategies for screening of veterinary drugs and their residues in edible products. J. Chromatoger., 667:1-20.

Egyptian Organization for Standardization "EOS" (2008): Maximum Residue Limits for Veterinary Drugs in Foods, ES: 3692/2008, ES: 3685/2008.

Feldman, D.; Ganon, J.; Huffman, R. and Simpsons, J. (2003): Solution for data analysis and presentation graphics, 2nd Ed. Abacus Lancripts, Inc., Barkeley, USA.

Food Agriculture Organization/World Health Organization (FAO/WHO) (1998): Evaluation of certain drug residues in food. Forty- Seventh report of the Joint FAO/WHO Expert Committee on Food Addit., pp. 22-26, Geneva.

Gergis-Aida F. (1998): Tetracycline residues in broiler carcasses. Beni-suef Vet. Med. Res., 3:159-172.

Gratacos Cubarsi, M.; Fernandez Garcia, A.; Pierre, P.; Valero-Pamplona, A.; Garcia-Regueiro, A. and Castellari, M. (2007): Formation of Tetracycline Degradation Products in Chicken and Pig Meat under Different Thermal Processing Conditions. J. Agric. Food Chem., 55:4610-4616.

Hagsama, N. (1992): Stability of veterinary drug residues during storage and processing. Proceeding of the European Residue Conference, Valdhoven, the Netherland, 1: 41-48.

Javadi, A. (2011): Effect of roasting, boiling and microwaving cooking method on Doxycline residues in edible tissues of poultry by microbial method. Afr. J. Pharm. Pharmacol., 5(8): 1034-1037.
Kibris A. (2007): Microbilogical screening method for detection of aminoglycosides, $\quad \beta$ - $\quad$ lactames, macrolides, tetracyclines and quinolones in meat samples. Slov Vet. Res., 44(1/2): 11-8.

Kühne, M.; Korner, U. and Wenzel, S. (2001): Tetracycline residues in meat and bone meals. Part 2: the effect of heat treatments on bound tetracycline residues. J. of Food Addit. Contam., 18:593-600.

Larkin, C.; Poppe, C.; Mcnab, B.; Mcewen, B. Madhi, A. and Odumeru, J. (2004): Antibiotic resistance of Salmonella isolated from hog, beef, and chicken carcass samples from provincially inspected abattoirs in Ontario. J. of Food Prot, 67:48-455.

Landoni, M. F. and Erreclade, J. O. (1992): "Tissue concentrations of a long-acting oxytetracycline formulation after intramuscular administration in cattle". Revue scientifique et technique. Off. Int. des Epizooties, 11: 909-915.

MacNeil, J. D.; Martz, V. K.; Korsrud, G. O.; Salisbury, C. D. C.; Oka, H.; Epstein, R. L. and Barnes, C. J. (1996): Chlortetracycline, oxytetracycline and tetracycline in edible animal tissues, liquid chromatographic method: Collaborative study. J. Assoc. Off. Anal. Chem. Int., 19: 405-417.

Mahgoub O., Kadim I.T., Ann M., Al Zadjali S. A. and Annamalaki K. (2006): Use of enzyme linked immunosorbent assay (ELISA) for detection of antibiotic and anabolic residues in goat and sheep meat. World J. Agric. Sci., 2 (3): 298302. 
Marouf, H. A. and Bazalou, M. S. (2005): Detection of antibiotic residues in meat sold in Damietta governorate. $4^{\text {th }}$ Int. Sci. Conf., Mansoura, 5-6 April: 509519.

Nguyen, V. H.; Li, M. Q.; Khan, M. A.; Li, C. B. and Zhou, G. H. (2013): Effect of cooking methods on tetracycline residues in pig meat. African J. of Pharm. and Pharmacol., 7(22):14481454.

Olufemi O. I. and Agboola E. A. (2009): Oxytetracycline residues in Edible tissues of Cattle Slaughtered in Akure, Nigeria. Internet J. Food Safety, 11: 6266.

Prescott, J. F. and Baggot, J. D. (1993): Antimicrobial therapy in veterinary medicine, $2^{\text {nd }}$ Ed. Iowa State University Press, Iowa, USA, pp: 215-228.

Rome. A. (1991): Residues of some veterinary drugs in animals and food. FAO/ Food and Nutrition papers, 97-119.

Rose, M. D.; Bygrave, J. and Shearer, G. (1996): The effect of cooking on veterinary drug residues in food: 4. Oxytetracycline Food Additives and Contaminants: Part A, 13(3):275-286.

Shahid M.A., Siddique M., Abu baker M., Arshed M. J., Asif M. and Ahmed A. (2007): Status of oxytetracycline residues in chicken Meat in Rawalpinidi/ Islamabad Area of Pakistan. Asian Journal of poultry Science. 1: 8-15.

Thomas, B. B. (1994): Veterinary Drug Therapy. "Text Book" $5^{\text {th }}$ Ed. Lea and Febiger, Awauerly Company Press, USA. 